\title{
ONE SNAKE OR TWO? EXPLORING MEDICAL SYMBOLS AMONG MEDICAL STUDENTS
}

\section{Kehinde Kazeem Kanmodi ${ }^{1-4}$, Oladimeji Adebayo ${ }^{5}$, Miracle Ayomikun Adesina ${ }^{1,6}$, Omotayo Francis FagBule ${ }^{1,2,7}$, Franklin EMERENINI ${ }^{8}$}

\author{
${ }^{1}$ Cephas Health Research Initiative Inc, Ibadan, Nigeria \\ ${ }^{2}$ Department of Dental and Maxillofacial Surgery, Usmanu Danfodiyo \\ University Teaching Hospital, Sokoto, Nigeria \\ ${ }^{3}$ Department of Planning Research and Statistics, Mental and Oral Health \\ Development Organization, Birnin Kebbi, Nigeria \\ ${ }^{4}$ World Health Organization, Kebbi State Field Office, Birnin Kebbi, Nigeria \\ ${ }^{5}$ Department of Medicine, University College Hospital, Ibadan, Nigeria \\ ${ }^{6}$ Department of Physiotherapy, University of Ibadan, Ibadan, Nigeria \\ ${ }^{7}$ Department of Periodontology and Community Dentistry, University College Hospital, \\ Ibadan, Nigeria \\ ${ }^{8}$ APIN Public Health Intiatives, Abuja, Nigeria
}

\begin{abstract}
A b s t r a c t
Background: Symbols play a very crucial role in the culture of a society, and the medical society is not an exception to this. In the world of Orthodox medicine, the Rod of Asclepius is regarded as the true symbol of medicine. However, there exists to be an issue of interchange of the correct medical symbol (i.e. Rod of Asclepius) with another similar symbol (i.e. the Caduceus). This study aims to explore medical students' knowledge and opinion on the appropriate symbol of medicine.

Methods: This study was a cross-sectional survey of 84 medical students at the Usmanu Danfodiyo University (UDU), North-West Nigeria. Study tool was a paper questionnaire. The collected data were analyzed using the Epi info 7 Software.

Results: The mean $( \pm \mathrm{SD})$ age of the participants was $23.7( \pm 3.4)$ years, $72.6 \%$ were males, and $73.8 \%$ were in their $4^{\text {th }}$ year. Only $59.5 \%$ had interest in non-medical literature. Also, only $6.0 \%$ had doctors as their parents. The majority $(88.1 \%)$ of the participants erroneously identified the Caduceus symbol as the most appropriate symbol of medicine. Furthermore, only 45.2\% indicated that the Rod of Asclepius and the Caduceus symbols originated from ancient Greece. Virtually all (97.6\%) the participants opined that the Caduceus symbol is the most popular symbol of Medicine. Finally, the majority (73.8\%) of the participants recommended that a course on the History of Medicine should be added to the medical curriculum of their school.

Conclusion: This study found that the majority of the surveyed medical students did not know much about the historically correct medical symbol. This shows the need for awareness creation on the true symbol of medicine among medical students, and even the public-at-large.
\end{abstract}

Keywords: Medical symbols, logo, Caduceus, Asclepius, students, Nigeria, university

\section{INTRODUCTION}

Symbols play a very important role in the societal culture and tradition, and, in fact, the medical profession is not an exception [1]. The symbol entailing an entwined snake and a staff (Figure 1) is the true symbol representing the medical profession and it has been in usage since $800 \mathrm{BC}$ [2-5]. However, it appears that there is confusion in the utility of medi-

Corresponding author: Dr. Kehinde Kazeem Kanmodi; e-mail: kanmodikehinde@yahoo.com

(C) 2019 Kehinde Kazeem Kanmodi et al.

This work is licensed under the Creative Commons Attribution-NonCommercial-NoDerivs 4.0 License

(https://creativecommons.org/licenses/by-nc-nd/4.0/) 
cal symbols used in the profession as the symbol with two entwining snakes around a winged staff (Figure 2) is being used instead of the one with a snake-entwined staff (Figure 1) [6-10].

The symbol depicting a single snake-entwined staff is called the Rod of Asclepius (Figure 1) [11-13]. Asclepius was a Greek man who lived in the sixth century BC and he was considered the hero-physician who performs miraculous acts of healing on the battlefield and thus his symbol was incorporated into the emblem carried by his followers [13, 14].

The symbol depicting two intertwined snakes around a rod (Figure 2) is called the Caduceus symbol. The Caduceus is the magical rod of the messenger god of the Greek pantheon, Hermes (Roman version of Mercury) [13]. Hermes was considered to be the patron of sports, merchants, peace, eloquence, and thieves; hence, the Caduceus symbol is a symbol of commerce and it is not that related to medicine [13, 15, 16].

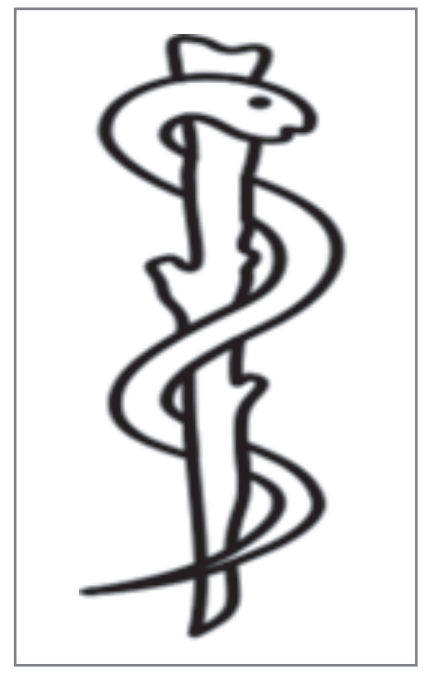

Fig. 1. Rod of Asclepius

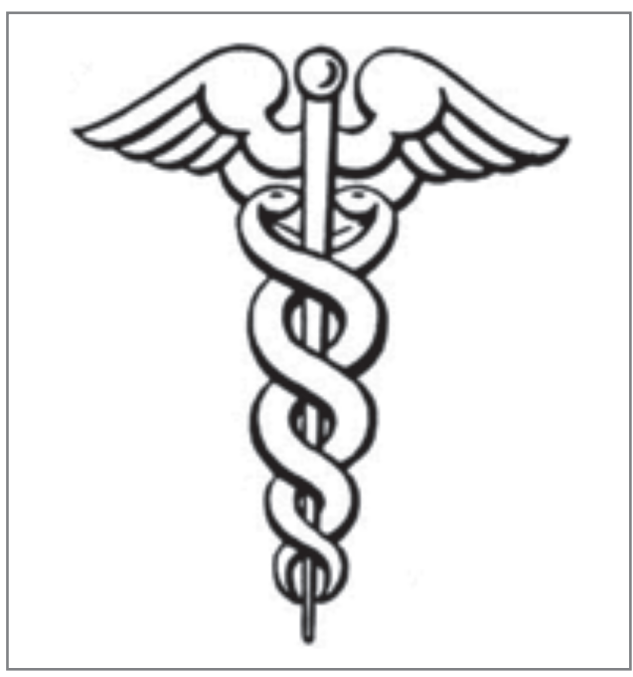

Fig. 2. Caduceus

Also, there exists a modified version of the Caduceus symbol; this version is called winged Caduceus [7, 15]. The most prominent organization using the modified version (winged caduceus) of this symbol is the US Medical Corps and the symbol is not regarded as a medical symbol but rather an administrative symbol [7, 15]. Also the US Public Health Services used it as their symbol because of their early ties with merchant seamen and the maritime industry [17].

There is enough evidence that the Rod of Asclepius is the correct symbol for medicine, if at all any symbol is to be used in medicine. However, the confusion over its use as the most appropriate medical symbol is not surprising, considering its similarity with the Caduceus symbol. In history, this erroneous interchangeability have been corrected, however the problem still appears to persist globally, Nigeria inclusive [6, 8, 10, 18]. Based on the aforementioned, it therefore becomes imperative for trainees and experts in the medical profession to have the correct knowledge of the true medical symbol.

In a scientific study conducted in India it was revealed that the students of medicine demonstrated poor knowledge of medical symbols [18]. Another recent study, though not conducted among medical students but rather among health professional schools in the US, Puerto Rico, and Canada, also revealed a popular use of the incorrect symbol of medicine [19]. Similarly, a previous survey in the US showed that $62 \%$ of the professional associations while $76 \%$ of commercial organizations used the Caduceus symbol [20]. 
Issues such as medical etymology, symbols, and history are not usually taught at medical schools, with Nigerian medical schools not being exempted, as no course on the history of medicine is found in the curriculum of Nigerian medical schools [21,22], rather many medical students and practitioners get to know them from self-enquiry. Based on the above discussions, we thereby aim to conduct a study exploring Nigerian medical students' knowledge of the correct medical symbol in order to provide more insight to the problem of interchangeability in Nigeria. This study thereby aims to: assess the level of knowledge of the medical students of the Usmanu Danfodiyo University (UDU), Sokoto, Nigeria, on the appropriate medical symbol (the Rod of Asclepius versus Caduceus); explore their capacity in identifying the true meaning of medical symbols; and to explore their opinion on the popularity of the medical symbols (the Rod of Asclepius versus Caduceus).

\section{METHODS}

The study was a cross sectional survey of the medical students attending the UDU, Sokoto Local Government Area (LGA), Sokoto State, Nigeria, which was conducted under compliance with the Helsinki Declaration on research involving human subjects. This university (i.e. UDU) is the home to the only medical school in the Sokoto State. The school runs a six-year medical degree program. This program has two phases which are the pre-clinical and the clinical phases; those students in the $1^{\text {st }}, 2^{\text {nd }}$, and $3^{\text {rd }}$ undergraduate years (UGYs) are in the pre-clinical phase while those in the $4^{\text {th }}, 5^{\text {th }}$, and $6^{\text {th }}$ UGYs are in the clinical phase. Those medical students that are in the clinical phase of their medical program are domiciled within the Usmanu Danfodiyo University Teaching Hospital (UDUTH), while those in the preclinical phase are domiciled within the university campuses. This hospital (UDUTH) is a tertiary hospital affiliated to the UDU. Both the hospital and the university campuses are situated within Sokoto LGA.

The study instrument used for the study was a 16-item questionnaire developed from literatures [1-21]. The questionnaire obtained information from the participants about their: demographic profile, status on having a medical doctor as a parent, interest in non-medical literature, knowledge of medical symbols (the Rod of Asclepius versus caduceus), and opinion on the popularity of medical symbols (the Rod of Asclepius versus caduceus).

A minimum sample size of 80 medical students was used for the study. Sample size was determined by convenience, due to limited resources to the authors. Only those medical students from $2^{\text {nd }}$ to $6^{\text {th }}$ UGYs were considered eligible to participate in this study because they started receiving lectures in medical courses, while the medical students in the $1^{\text {st }}$ UGY were exempted because they were still in their preliminary year of study. Using a multistage sampling technique, only those medical students in the $4^{\text {th }}$ and the $5^{\text {th }}$ UGYs were selected for the study. However, a simple random sampling technique was used in the recruitment of those medical students in the selected classes (i.e. those who were in their $4^{\text {th }}$ and the $5^{\text {th }}$ UGYs) for interview.

The participants were approached at their classrooms and they were informed about the purpose of the study. They were also informed that their participation was voluntary and anonymous. No participant was harmed in the course of the study. Verbal informed consent was obtained from each participant prior to their participation in the study. Out of 100 medical students approached, a total of 84 participants agreed to participate in the study. These consenting participants were interviewed using a self-administered questionnaire. The data for this study was collected in February 2018.

The collected data was cleaned, coded and entered into Epi info 7 Software, and stored in the same. The data was analyzed using the same software. Test of associations between the variables was done using Chi square test, with a p-value $<0.05$ considered to be statistically significant. The results of the data analysis were presented using tables. 


\section{RESULTS}

The response rate for the study was $84 \%$. The mean $( \pm \mathrm{SD})$ age of the 84 participants that took part in this study was $23.7( \pm 3.4)$ years, $72.6 \%$ were males, $81.0 \%$ were Muslims, and $73.8 \%$ were in their $4^{\text {th }}$ UGY (Table 1$)$.

Table 1. Socio-demographic profile of participants

\begin{tabular}{|c|c|c|}
\hline Characteristics $(n=84)$ & Frequency & $\%$ \\
\hline \multicolumn{3}{|l|}{ Age (in years) } \\
\hline Mean & 23.7 & $\mathrm{~N} / \mathrm{A}$ \\
\hline $\mathrm{SD}$ & \pm 3.4 & $\mathrm{~N} / \mathrm{A}$ \\
\hline \multicolumn{3}{|l|}{ Gender } \\
\hline Male & 61 & 72.6 \\
\hline Female & 19 & 22.6 \\
\hline Prefer not to say & 2 & 2.4 \\
\hline No response & 2 & 2.4 \\
\hline \multicolumn{3}{|l|}{ Religion } \\
\hline Christianity & 12 & 14.3 \\
\hline Islam & 68 & 81.0 \\
\hline Traditional & 2 & 2.4 \\
\hline No response & 2 & 2.4 \\
\hline \multicolumn{3}{|l|}{ UGY } \\
\hline $4^{\text {th }}$ & 62 & 73.8 \\
\hline $5^{\text {th }}$ & 21 & 25.0 \\
\hline No response & 1 & 1.2 \\
\hline
\end{tabular}

n - Total number of participants, N/A - Not applicable, SD - Standard deviation, UGY Undergraduate year

Only $59.5 \%$ of the participants had interest in non-medical literature; only $6.0 \%$ had doctors as their parents. Less than a third (27.4\%) of the participants knew Figure 1 as the Rod of Asclepius by name while only $45.2 \%$ considered the symbol to be the most appropriate medical symbol. Furthermore, less than one-quarter (21.4\%) of them could identify the Rod of Asclepius as the historically correct medical symbol. Only $45.2 \%$ of the participants knew that the Rod of Asclepius originated from ancient Greece. Less than one-fifth (17.9\%) of the participants had an item having the Rod of Asclepius symbol on it. However, the majority (73.8\%) of the participants recommended that a course on the History of Medicine should be in the medical curriculum (Table 2). 
Table 2. Frequency distribution of responses given by the participants on information pertaining to medical symbols

\begin{tabular}{|l|l|l}
\hline Variables & Frequency & $\%$ \\
\hline
\end{tabular}

Do you have interest in non-medical literature? $(\mathrm{N}=84)$

\begin{tabular}{|l|c|r|}
\hline Neutral & 16 & 19.0 \\
\hline No & 14 & 16.7 \\
\hline Yes & 50 & 59.5 \\
\hline No response & 4 & 4.8 \\
\hline
\end{tabular}

Is your parent a doctor? $(\mathrm{N}=84)$

\begin{tabular}{|l|c|c|}
\hline No & 73 & 86.9 \\
\hline Yes & 5 & 6.0 \\
\hline No response & 6 & 7.1 \\
\hline
\end{tabular}

Which of the following symbols is the most appropriate symbol of Medicine? $(\mathrm{N}=84)$

\begin{tabular}{|l|c|r|}
\hline Figure 1 & 4 & 4.8 \\
\hline Figure 2 & 74 & 88.1 \\
\hline No response & & \\
\hline
\end{tabular}

Figure 1 is historically the correct symbol of Medicine. $(\mathrm{N}=84)$

\begin{tabular}{|l|c|c|}
\hline No & 18 & 21.4 \\
\hline Yes & 18 & 21.4 \\
\hline I don't know & 45 & 53.6 \\
\hline No response & 3 & 3.6 \\
\hline
\end{tabular}

Figure 2 is historically the correct symbol of Medicine. $(\mathrm{N}=84)$

\begin{tabular}{|l|c|c|}
\hline No & 1 & 1.2 \\
\hline Yes & 27 & 32.1 \\
\hline I don't know & 54 & 64.3 \\
\hline No response & 2 & 2.4 \\
\hline Figure 1 is called rod of Asclepius. (N=84) & 4 & 4.8 \\
\hline No & 23 & 27.4 \\
\hline Yes & 51 & 60.7 \\
\hline I don't know & 6 & 7.1 \\
\hline No response & & \\
\hline
\end{tabular}


Figure 2 is called Caduceus. $(\mathrm{N}=84)$

\begin{tabular}{|l|c|r|}
\hline No & 1 & 1.2 \\
\hline Yes & 27 & 32. \\
\hline I don't know & 54 & 2.4 \\
\hline No response & 2 & 2.4 \\
\hline
\end{tabular}

Where did these symbols originate from? $(\mathrm{N}=84)$

\begin{tabular}{|l|c|r|}
\hline Ancient Greece & 38 & 45.2 \\
\hline Ancient Rome & 15 & 17.9 \\
\hline Babylon & 1 & 1.2 \\
\hline No response & 30 & 35.7 \\
\hline
\end{tabular}

Which of the symbol in your opinion is more popular? $(\mathrm{N}=84)$

\begin{tabular}{|c|c|c} 
Figure 1 & 2 & 2.4 \\
\hline Figure 2 & 82 & 97.6
\end{tabular}

Do you have any item e.g. ward coat, textbook or any item with figure 1 ? $(\mathrm{N}=84)$

\begin{tabular}{|l|c|c|}
\hline No & 59 & 70.2 \\
\hline Yes & 15 & 17.9 \\
\hline No response & 10 & 11.9 \\
\hline
\end{tabular}

Do you have any item e.g. ward coat, textbook or any item with figure 2 ? $(\mathrm{N}=84)$

\begin{tabular}{|l|c|c|}
\hline No & 10 & 11.9 \\
\hline Yes & 72 & 85.7 \\
\hline No response & 2 & 2.4 \\
\hline Should a course on history of medicine be in the medical curriculum? (N=84) \\
\hline No & 10 & 11.9 \\
\hline Yes & 62 & 73.8 \\
\hline Undecided & 4 & 4.8 \\
\hline No response & 8 & 9.5 \\
\hline
\end{tabular}

$\mathbf{N}$ - Total number of participants in each category 
Lastly, there is no statistically significant relationship between the participants' opinion on the most appropriate medical symbol and their interest in non-medical literature $(p$-value $=0.480)$ and the status of having a doctor as a parent $(p$-value $=0.675)($ Table 3$)$.

Table 3. Association between participants' background and knowledge of the most appropriate symbol of Medicine

\begin{tabular}{|c|c|c|c|}
\hline \multirow[t]{2}{*}{ Variables } & \multicolumn{2}{|c|}{ Which of the following symbols is the most appropriate symbol of Medicine? } & \multirow[t]{2}{*}{ p-value } \\
\hline & Rod of Asclepius $(\mathrm{N}=4)$ & Caduceus $(\mathrm{N}=74)$ & \\
\hline \multicolumn{4}{|c|}{ Do you have interest in non-medical literature? } \\
\hline Neutral & $2(50.0)$ & $12(16.2)$ & \multirow[t]{3}{*}{0.480} \\
\hline No & $0(0.0)$ & $14(18.9)$ & \\
\hline Yes & $2(50.0)$ & $44(59.5)$ & \\
\hline \multicolumn{4}{|c|}{ Is your parent a doctor? } \\
\hline No & $4(100.0)$ & $64(86.5)$ & \multirow[t]{2}{*}{0.675} \\
\hline Yes & $0(0.0)$ & $4(5.4)$ & \\
\hline
\end{tabular}

$\mathbf{N}$ - Total number of participants in each category

\section{DISCUSSION}

It is a known fact that many medical institutions are still erroneously using the incorrect symbol of medicine as their institutional symbol [19, 20]. Similarly, many medical practitioners and trainees are yet to know the correct symbol of medicine [13, 18, 19]. The correct symbol of medicine is the Rod of Asclepius [13, 14]. Due to recent awareness creation on the correct medical symbol many medical institutions had changed their symbol to the correct one [18]. As some, if not so many, medical institutions are yet to change their medical symbol to the correct one; this shows that much work still needs to be done in creating institutional awareness on the correct medical symbol [18, 19].

This present study was conducted with the strict rationale of assessing the level of knowledge and perception of medical students on the appropriate medical symbol (the Rod of Asclepius versus Caduceus). However, this study was conducted not with the intention to belittle the choice of the Caduceus (the wrong symbol) as a medical symbol, rather to correct the incorrect assumption and claim back a part of the beautiful heritage and legacy of medicine. The findings made in this study are very interesting. In the institution where this study was conducted, the History of Medicine was not a course in its academic curriculum for medical students. This particular finding supports the report of Prakash and Johnny, who in their paper reported that medical symbols were not taught at medical schools [21]. However, the majority of the participants found the introduction of this course into the medical curriculum as a need and thereby recommended that the History of Medicine should be included into the curriculum of their medical school as a course. The idea of incorporation of this course into medical schools' curriculum is a good one, as many of these medical trainees will get to know more about the historical heritage of medicine.

It is noteworthy that the majority of our study participants were unable to correctly identify the true symbol of medicine. This finding is closely similar to what was reported among 
their counterparts in Indian medical schools [18]. However, by comparing statistics, we observed that the proportion of those participating medical students in our study, who were not knowledgeable of the true symbol of medicine, was higher than that recorded among those Indian medical students (75\% versus 66\%). Also, only $45.2 \%$ of our study participants indicated that these two debated medical symbols (the Rod of Asclepius versus Caduceus) originated from ancient Greece; this shows that many of them lacked knowledge of the historical origin of these symbols. However, if medical students could find it difficult to know the correct medical symbol, then worse should be expected from the lay public.

From the bivariate analysis comparing the participants' background (such as "having interest in non-medical literature" and "having a doctor as a parent") and knowledge of the most appropriate symbol of medicine, we recorded no statistically significant association between the two variables. This suggests that these three factors do not have profound influence on medical students' knowledge of the correct medical symbol.

It is also noteworthy that virtually all the participants in this present study were of the opinion that the Caduceus symbol is the most popular symbol of medicine. The reason behind this erroneous opinion is not far-fetched, as most of them had an item having the Caduceus symbol on it; hence, making them to believe that the Caduceus symbol is the most appropriate. Also, a research had shown that the Caduceus is a more popular symbol than the Rod of Asclepius in many medical schools [19]. Since many medical schools are still using the Caduceus symbol as their medical symbol, invariably the symbol will be the more popularly inscribed symbol of medicine on the items (such as books, lab coats, etc.) of students of such medical schools.

This study has its limitation. First, this study was a single-center study. This study did not survey medical students of other medical schools; hence, it is very difficult to make generalizations based on the findings made in this study. Second, only medical students were surveyed in this study; this study did not assess the knowledge of medical professionals on medical symbol. Hence, this shows the need to conduct a similar study among medical professionals in Nigeria.

However, based on the findings made in this study, the authors recommend that the History of Medicine should be introduced as a course into the academic curriculum of the surveyed medical school, and even in other Nigerian medical schools. The incorporation of this course will not only go a long way in providing information to medical students on the history of medicine alone, but also give them an in-depth knowledge of the evolutional history of medicine as a noble profession. Also, based on the findings made in this study, it also becomes imperative to educate the public on the correct medical symbol as well.

\section{CONCLUSION}

The majority of the surveyed medical students did not know much about the historically correct medical symbol; however, many of them recommended that the History of Medicine into the academic curriculum of the Human Medicine program of their school. Hence, this shows the need for awareness creation on the true symbol of medicine among medical students, and even the public-at-large.

\section{REFERENCES}

1. Nayernouri T. Asclepius, Caduceus, and Simurgh as Medical Symbols: Part I. Arch Iran Med 2010;13(1):61-8.

2. Rakel RE. One snake or two? JAMA 1985;253(16):2369.

3. Retief FP, Cilliers L. Snake and staff symbolism, and healing. South African medical journal. 2002;92(7):553-6. 
4. Young P, Finn BC, Bruetman JE, Cesaro Gelos J, Trimarchi H. Rod of Asclepius. Symbol of medicine. Rev Med Chil 2013;141(9):1197-201.

5. Medicine's logo. Can Med Assoc J 1969;100(22):1064.

6. Adebayo O, Fagbule F, Oyabambi A. Caduceus or rod of aesculapius: revisiting erroneous interchangeability. Ann Ib Postgrad Med 2017;15(1):65-66.

7. Baird KA. The caduceus symbol. Can Med Assoc J 1965;92(19):1038.

8. Sacks AC, Michels R. Images and Asclepius. Caduceus and Asclepius: History of an error. Am J Psychiatry 2012;169(5):464.

9. Wilcox RA, Whitham EM. The symbol of modern medicine: why one snake is more than two. Ann Intern Med 2003;138(8):673-7.

10. Fromson JA. The Asclepius: The Ancient Standard of Physicians. Am J Psychiatry $2011 ; 168(7): 752$.

11. Capodicasa E. What symbol should represent the medical profession? Lancet 364(9432):416.

12. Subbarayappa BV. The roots of ancient medicine: an historical outline. J BioSci 2001;26(2):13553.

13. Hinek A, Backstein R. The magic wands of medicine. Univ Toronto Med J 2004;82(1):68-70.

14. Hart GD. Asclepius, God of Medicine. Can Med Assoc J 1965;92(5):232-6.

15. Adebayo O. Symbols of Medicine. History of Medicine: A glimpse a work and a world .Ilorin: Insight \& Project; 2006.

16. Kritikos A, Bekiari A, Famissis K, Nikitaras N, Sakellariou K. Asclepius. The" anax of trikki" as a symbol of sports education. Studies Physical Culture Tour 2008;15:2.

17. Hause D. The symbol of modern medicine. Ann Intern Med 2004;140(4):3117.

18. Shetty A, Shetty S, Dsouza O. Medical Symbols in Practice: myths vs reality. J Clin Diagn Res 2014;8(8):PC12-PC4.

19. Hamann C, Martelon M. Branding Asklepios and the traditional and variant serpent symbol display among health professional schools in the United States, Puerto Rico, and Canada: A CrossSectional Survey. JMIR Med Educ 2016;2(1):e6.

20. Friedlander WJ. The Golden Wand of Medicine: A History of the Caduceus Symbol in Medicine. New York: Greenwood Press; 1992.

21. Prakash M, Johnny JC. Things you don’t learn in medical school: Caduceus. J Pharm Bioallied Sci 2015;7(Suppl 1):S49-S50.

22. College of Medicine, University of Ibadan, Prospectus 2006-2008. Ibadan: University of Ibadan Printing Press. ISBN 978-2194-73-5. 


\section{APPENDIX I}

\section{EXPLORING MEDICAL SYMBOLS AMONG MEDICAL STUDENTS}

Kindly tick or fill as appropriate

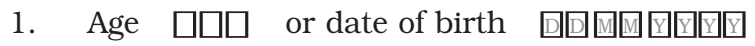

2. Sex $\square_{1}$ Male $\square_{2}$ Female $\square_{3}$ Transgender $\square_{4}$ Prefer not to say

3. Religion $\square_{1}$ Christianity $\square_{2}$ Islam $\square_{3}$ Traditional religion $\square_{4}$ Others

4. Level $\square_{1} 200 \mathrm{~L} \quad \square_{2} 300 \mathrm{~L} \quad \square_{3} 400 \mathrm{~L} \quad \square_{4} 500 \mathrm{~L} \quad \square_{5} 600 \mathrm{~L}$

5. Is any of your parents a doctor? $\quad \square_{1}$ Yes $\quad \square_{2}$ No

6. Do you have any interest in non-medical literature $\quad \square_{1}$ Yes $\quad \square_{2}$ No $\quad \square_{3}$ Neutral

7. Which of the following symbol is the most appropriate symbol of Medicine? Tick the most appropriate figure

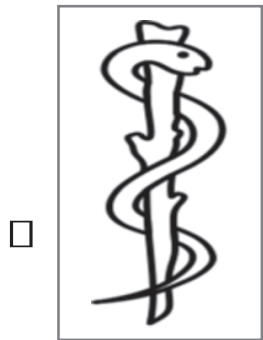

Figure 1. Rod of Asclepius

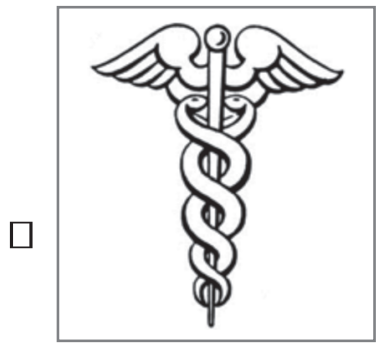

Figure 2. Caduceus

8. Figure 1 is historically the correct symbol of medicine $\quad \square_{1}$ Yes $\quad \square_{2}$ No $\quad \square{ }_{3}$ I don't know

9. Figure 2 is historically the correct symbol of medicine $\quad \square_{1}$ Yes $\quad \square_{2}$ No $\quad \square{ }_{3}$ I don't know

10. Figure 1 is called Rod of Aesculapius $\quad \square_{1}$ Yes $\quad \square_{2}$ No $\quad \square_{3}$ I don't know

11. Figure 2 is called Caduceus $\square_{1}$ Yes $\quad \square_{2}$ No $\quad \square{ }_{3}$ I don't know

12. Which is of the symbol in your opinion is more popular? $\quad \square_{1}$ Figure $1 \quad \square_{2}$ Figure 2

13. Do you have any item e.g. ward coat, textbook or any item with figure 1 ? $\square_{1}$ Yes $\quad \square_{2}$ No

14. Do you have any item e.g. ward coat, textbook or any item with figure 2? $\square_{1}$ Yes $\quad \square_{2}$ No

15. Should a course on history of medicine be in the medical curriculum? $\square_{1}$ Yes $\quad \square{ }_{2}$ No

16. Where did these symbols originate from?

$\square$ Ancient Rome

$\square$ Ancient Greece

Babylon

State if it is others, state here

Thank you for your time. 